\title{
El tratado modificado de reciprocidad comercial entre Venezuela y los Estados Unidos
}

\begin{abstract}
HELIODOROL. CLAVERIERODRÍGUEZ, PEDRO LUIS EchEVERrí Y JOVITO A. VILLALBa Vera son especialistas de CORDIPLAN, el Instituto de Comercio Exterior y el Banco Central de Venezuela, respectivamente. El trabajo que aquí se publica no refleja, necesariamente, el punto de vista de las instituciones mencionadas.
\end{abstract}

\section{¿QUIEN VIOLÓ EL TRATADO?}

ANTECEDENTES

Finalizada la II Guerra Mundial, la industria de los países beligerantes enfrentaba los típicos problemas del cambio de una producción de bienes bélicos a otra más adecuada a los tiempos de paz.

De ellos, Estados Unidos estaba en mejores condiciones para alcanzar rápidamente sus niveles normales de producción. Además la coyuntura internacional le favorecía. En efecto, la aplicación del Plan Marshall impulsó el sector externo (exportador) de la economía norteamericana en forma creciente. Los primeros años de postguerra fueron brillantes para la Balanza Comercial de los Estados Unidos. El proceso de reconstrucción europeo y japonés se edificó sobre las bases de los productos norteamericanos. El oro como medio de pago internacional afluía hacia las bóvedas del Banco de la Reserva Federal. Para 1949 las reservas en oro de los Estados Unidos se sitúan en el orden de los 24.000 millones de dólares. El poder político y económico de este gran imperio capitalista alcanzaba su punto máximo de esplendor hegemónico indiscutido.

Ubicado en este contexto económico y político aparece la firma del "Tratado modificado de reciprocidad comercial entre los Estados Unidos de Venezuela y los Estados Unidos de América", con fecha 28 de agosto de 1952. 
Bajo los auspicios de un régimen dictatorial de derecha, Venezuela: cambiaba el rumbo en su política internacional y sus gobernantes deseaban estimular la inversión extranjera, en particular de empresas. petroleras.

El Tratado de 1952 modifica el hasta entonces vigente del 6 de: noviembre de 1939. Por el primer Tratado (1939) los gravámenes. que pagaban las importaciones petroleras provenientes de Venezuela se reducen a la mitad, o sea 10,5 centavos de dólar por barril (por la ley "Revenue Act", 1932, Estados Unidos gravaba sus importaciones de petróleo con un impuesto de 21 centavos de dólar por barril) . A pesar de que se concede este desgravamen, se somete el petróleo, venezolano a una cuota equivalente al $5 \%$ de lo refinado durante el año anterior por la inclustria norteamericana. El excedente pagaría la tarifa normal de 21 centavos de dólar. Conviene mencionar que para aquel entonces Estados Unidos era autosuficiente en petróleo. Sus importaciones petroleras constituían exclusivamente materia prima para la producción de derivados exportables.

Las características del Tratado de 1939 pueden sintetizarse en el interés venezolano por desarrollar rápidamente sus recursos petroleros y el no menor interés norteamericano por aumentar sus importaciones, sin desestimar las inversiones crecientes de sus empresas. que ya operaban en Venezuela.

En la postguerra Ios efectos negativos del Tratado de 1939 se: hicieron tan evidentes que Venezuela solicitó su revisión. En 1948 . los Estados Unidos, por primera vez en su historia, dejan de ser autosuficientes en recursos petroleros. Venezuela buscaba la manera de ganar ese mercado potencial pero la cuota fijada en 1939 le impedía conseguirlo, además que resultaba de imperiosa necesidad la protección de las industrias incipientes.

\section{CARAGTERÍSTICAS DEL TRATADO MODIFICADO DE 1952}

Dos listas de productos anexas al texto del Tratado modificado de 1952 constituyen el objeto específico del Convenio. La número uno; una larga lista de 182 rubros, muchos de ellos de gran amplitud, que incluyen desde garbanzos, queso y frutas hasta aeroplanos y maquinarias, pasando por jabones, biberones y paracaídas. Es la lista norteamericana de productos que podían exportar a Venezuela con preferencias arancelarias.

La lista número dos, de 21 productos venezolanos se reduce a petróleo y derivados, hierro, cacao, café, bóñiga, raíces de barbasco, tinturas de dividive, balatá y orquídeas.

La concesión fundamental que Venezuela obtiene es la eliminación 
de ta curota establecida en el Tratado cle 1939 para sus productos petroleros. Venezuela obtiene un mejor tratamiento para su petróleo, !mejor tratamiento que tiene la característica de conceder a Venezzuela lo que ya le correspondía por la cláusula de más favor, es ‘decir, el petróleo venezolano debería gozar de las mismas prerrogativas que ya recibían México y Canadá en materia petrolera; por rotra parte, no se debe olvidar que no discriminar contra las importaciones de cruclo provenientes de Venezuela era en cierto modo una forma más adecuada de tratar en las fronteras de USA a un pro- ducto de empresas norteamericanas domiciliadas en nuestro territorio y que por consiguiente eran ventajas para los mismos intereses norteamericanos, independientemente de que los nuestros obtuvieran algún beneficio. El mejor tratamiento para el petróleo de Vene.zuela se sintetiza en mantener la tarifa reducida de 10,5 centavos de dólar por barril para los crudos medianos y ligeros. A los pesados y fuel-oil se les aplica la tarifa mínima autorizada por la ley americana, 5,25 centavos de dólar por barril.

Los productos incluidos en ambas listas recibirán en los respectivos países importadores “... un tratamiento no menos favorable que el acordado al artículo semejante de origen nacional, con respecto a todas las leyes, reglamentos y requisitos que afecten su venta interna, su oferta en venta, su compra, transporte, distribución o uso..." (art. 5 bis). No se admite para dichos productos "... ninguna prohibición, restricción o cualquier otra forma de regulación cuantitativa..." (Art. 6) ${ }^{1}$ de parte de cualquiera de los dos gobiernos.

Por otra parte, en el articulado del Tratado hay una cláusula destinada a enfrentar situaciones de perjuicio grave a la economía de los países por causa de una importación significativamente grande y de fuerte impacto desequilibrador sobre la industria doméstica fabricante de "productos semejantes o productos directamente competidores". En esos casos ambos gobiernos "quedarán en libertad con respecto al referido producto, en la medida y por el tiempo que sea necesario para prevenir o remediar tal perjuicio, de suspender la obligación en su totalidad o en parte, de retirar o modificar la concesión" (Art. 13 bis).

Esta cláusula responde a una disposición legal de los Estados Unidos, debe ser incluida en todos los convenios que ese país firme. Incluso el GATT acepta la excepción (Art. XIX del GATT); .es importante destacar, para los fines que veremos más adelante, que Venezuela no forma parte del GATT así como ninguno de los países grandes exportadores de petróleo.

ISubrayado nuestro. 
La cláusula de "nación más favorecida" quedó establecida en los artículos 9 y 10 del Tratado con Ios Estados Unidos. Por lo estipulado en dicha cláusula se dispone que las concesiones de favor a otros países automáticamente han de ser aplicadas a los firmantes del convenio, Venezuela y los Estados Unidios.

Por otra parte, como consecuencia de la cláusula de más favor contenida en el Acuerclo del GATT, Estados Unidos extiende a todos los países signatarios del mismo las ventajas de la lista No 2 del Tratado con Venezuela, y todavía más, las extiende a todos los países que no discriminan contra su comercio. Por tanto, las ventajas de la Lista No 2 dejaron de ser ventajas porque ya no favorecían sólo a Venezuela, sino a Todos los países exportadores de petróleo si éstos en su política comercial no hacían discriminación a los productos norteamericanos.

\section{ESTADOS UNIDOS VIOLA EL TRATADO}

La década 1950-1960, marca un extraordinario incremento de productividad para países como Japón, Alemania, Holanda, Francia e Italia. Este crecimiento industrial más los gastos de la guerra de Corea, de la guerra fría y posteriormente del Viet Nam, han provocado un déficit crónico en la balanza de pagos de los Estados Unidos y la consiguiente merma sustancial de sus reservas de oro. En 1964 las reservas se situaron en 15.000 millones de dólares y para fines del 71 apenas alcanzaban los 10.000 millones.

Dentro de esta tendencia que ya en 1958 era clara a pesar del paliativo que supuso el cierre del Canal de Suez (1956-57), se encuadra el sistema restriccionista de los Estados Unidos referente al petróleo. En efecto, en 1957, el presidente Eisenhower solicitó una reducción "voluntaria" de las importaciones petroleras. A pesar de la protesta venezolana se establece en 1958 un "Programa de restricciones voluntarias".

En marzo de 1959 se impuso el "Programa obligatorio de importaciones". El tratado con Venezuela quedaba así quebrantado unilateralmente. Fueron impuestas cuotas obligatorias, limitando las importaciones de crudo y derivados al $9 \%$ de las ventas nacionales correspondientes al año 1957. Las importaciones terrestres provenientes de México y Canadá quedaron exentas de esta limitación. Ello constituía una medida claramente discriminatoria contra Venezuela.

Herido el Tratado por iniciativa norteamericana, Venezuela reacciona estableciendo restricciones cuantitativas a productos incluidos 
en la Lista $N$ Y I, con el atenuante de no ser discriminatorias como las de Estados Unidos. La medida persigue, principalmente, favorecer la instalación de nuevas industrias conforme a los lineamientos de una política de sustitución de importaciones.

\section{CONTINÚAN LAS VIOLACIONES}

En 1962, el presidente Kennedy implantó un Programa de Restricciones Petroleras aún más discriminatorio y violatorio del Tratado. El cambio sustancial respecto de la política restriccionista de Eisenhower consiste en la inclusión de los volúmenes importados "por via terrestre" desde Canadá y México en la cuota global de importación (12,1 \% de la producción nacional), con el agravante de que las cantidades exportadas descle Ganadá y México no están sometidas a ningún poicentaje de participación en la cuota total. Esto significa que en la medida que aumenten las importaciones desde Canadá y México, otro tanto desciende la participación alícuota de los demás países proveedores. Cabría aquí formularnos una pequeña reflexión: ¿Cómo queda el Artículo 6 del Tratado con Venezuela, que no admite "ninguna prohibición, restricción o cualquier. otra forma de regulación cuantitativa"...?

Veamos a continuación cómo ha venido descendiendo la participación relativa de Venezuela en la importación de crudo y productos refinados efectuada por: los Estados Unidos.

Venezuela*: Exportación de Crudo y Productos Refinados a Estados Unidos (En miles de barriles diarios)

\begin{tabular}{cccccc}
\hline Año & $\begin{array}{c}(1) \\
\text { crudo }\end{array}$ & $\begin{array}{c}(2) \\
\text { Fueloil }\end{array}$ & $\begin{array}{c}(3) \\
\text { otros } \\
\text { Productos }\end{array}$ & $\begin{array}{c}(4)=(2+3) \\
\text { total } \\
\text { refinados }\end{array}$ & $\begin{array}{c}(5)=(1+4) \\
\text { Gran total }\end{array}$ \\
\hline 1959 & 537 & 529 & 142 & 671 & 1.208 \\
1960 & 553 & 568 & 109 & 677 & 1.230 \\
1961 & 500 & 564 & 132 & 696 & 1.196 \\
1962 & 463 & 604 & 136 & 740 & 1.203 \\
1963 & 478 & 591 & 140 & 731 & 1.209 \\
1964 & 476 & 648 & 142 & 790 & 1.266 \\
1965 & 432 & 779 & 144 & 923 & 1.355 \\
1966 & 403 & 808 & 152 & 960 & 1.363 \\
1967 & 359 & 783 & 154 & 937 & 1.296 \\
1968 & 344 & 762 & 172 & 934 & 1.278 \\
\hline
\end{tabular}

- Incluye Aruba y Curazao

FUENTE: USA, Publicación del Bureau of Mines. 
La participación relativa de Venezuela en las importaciones petroleras de los Estados Unidos, pasó de $65 \%$ en 1959, a $45 \%$ en 1968. Según las estimaciones del Ministerio de Minas e Hidrocarburos de Venezuela, las exportaciones hacia los Estados Unidos, debieron haber sido 1.841 .000 barriles diarios en 1968, en Iugar de 1.278.000, como aparece en el cuadro anterior.

Hace apenas algunos meses, noviembre de 1971, el presidente Nixon concedió al secretario del Interior la facultad de eliminar la norma establecida de que la cuota de combustible de calefacción debería cumplirse con la refinación de crudos hemisféricos y también con la importación descle refinerías dentro del hemisferio. Esta es la única concesión que le quedaba a Venezuela y está a punto de desaparecer. El Tratado de 1952, en sus aspectos petroleros tan vitales para Venezuela, estaba de hecho no solamente roto, sino ya constituía una afrenta para nuestro país.

La denuncia del Tratado por parte de Venezuela fue notificada oficialmente al embajador de los Estados Unidos en Caracas el 31 de diciembre de 1971 .

VENTAJAS Y DESVENTAJAS DEL TRATADO DE 1952

VENTAJAS PARA LOS ESTADOS UNIDOS

\section{i) Seguridad en el suministro}

La lista No 2 del Tratado, es la lista de las concesiones que otorgan los Estados Unidos a Venezuela, en su estructura predominan el petroleo y el hierro. ¿Era necesario firmar en 1952 un tratado para exportar materias primas de alto interés para los Estados Unidos? Un país que participa en la guerra de Corea y se lanza a una carrera armamentista ¿no precisaba acaso petróleo e hierro cercanos? ¿Quién hace el favor a quién? La posición geográfica de Venezuela respecto a los Estados Unidos y su gran dotación de recursos en ambos productos, proporcionaron y aún siguen ofreciendo un. "diferencial de seguridad" frente a otros abastecedores más lejanos, ubicados en zonas permanentemente conflictivas.

\section{ii) Inversiones de alta rentabilidad}

Veamos la relación capital/beneficios de la industria petrolera: 
(Millones de Bolivares)

\begin{tabular}{lcccccc}
\hline Año & $\begin{array}{c}\text { Capital } \\
\text { promedio }\end{array}$ & $\begin{array}{c}\text { Activo fijo } \\
\text { neto } \\
\text { promedio }\end{array}$ & $\begin{array}{c}\text { Depre- } \\
\text { ciación }\end{array}$ & $\begin{array}{c}\text { Otili- } \\
\text { dsdes } \\
\text { netas }\end{array}$ & $\begin{array}{c}\text { \% Rendi- } \\
\text { miento } \\
\text { sobre el } \\
\text { capital }\end{array}$ & $\begin{array}{c}\text { \% Rendi- } \\
\text { miento } \\
\text { sobre el } \\
\text { actiro } \\
\text { fijo-neto }\end{array}$ \\
\hline 1950 & 5.872 & 5.027 & 420 & 970 & 16,52 & 19,30 \\
1957 & 8.579 & 8.013 & 812 & 2.744 & 32,33 & 34,62 \\
1965 & 8.456 & 7.666 & 965 & 2,634 & 31,15 & 34,36 \\
1967 & 7.388 & 6.810 & 974 & 2.514 & 34,03 & 36,92 \\
1968 & 7.393 & 6.714 & 937 & 2.653 & 39,51 & 39,51 \\
1969 & 7.890 & 6.974 & 917 & 2.512 & 30,57 & 36,14 \\
\hline
\end{tabular}

FUENTE: Instituto de Comercio Exterior. "La inversión extranjera en Venezuela", Caracas, 1971.

Las tasas de rentabilidad de las compañías petroleras extranjeras, la mayoría norteamericanas (en la Shell hay también inversiones norteamericanas) oscilan entre un $30 \%$ y $40 \%$. En otras palabras, los inversionistas en petróleo obtienen anualmente en Venezuela beneficios que alcanzan un tercio de la inversión no amortizada. Es de hacer notar que los datos señalados son promedios para toda la industria petrolera. Hay casos como el de la Greole, cuyos rendimientos superan esta cifras. Conviene señalar, que los rendimientos promedios de la industria petrolera dentro de los Estados Unidos no alcanzan el $12 \%$

En diez años (1960-1969), la industria petrolera ha realizado una inversión de 3.644 millones de bolívares. Por concepto de depreciación y amortización acumuladas se han reembolsado 15.294 millones de bolívares y las utilidades netas de esos años suman Bs. 21.411 millones (cifras Banco Central de Venezuela. Informe Económico 1969, Cuadro A-119). Estos datos noș clan el índice de la cantidad de dinero que sale de Venezuela, ventaja incontrastable en favor de los Estados Unidos.

Según el informe especial del Banco Central de Venezuela, octubre 1971, todas las empresas norteamericanas, incluidas también las no petroleras, que operan en el país, remitieron a los Estados Unidos un total de Bs. 24.252 millones en el lapso 1960-1969.

iii) Exportación de productos norteamericanos incluidos en la Lista No I ,

Vamos a presentar un cuadro del valor de las exportaciones norteamericanas a Venezuela, referido a la lista No l del Tratado. 
Importación de Mercancias incluidas en la Lista No 1 del Tratado Modificado de Reciprocidad Comercial con los Estados Unidos Periodo 1962-1968 (Millones de bolivares)

\begin{tabular}{|c|c|c|c|c|}
\hline SECTORES & $\begin{array}{l}\text { Imp. pro- } \\
\text { renientes } \\
\text { do USA }\end{array}$ & $\begin{array}{l}\text { Imp. pro- } \\
\text { renientos } \\
\text { del Resto } \\
\text { del Mrundo }\end{array}$ & $\begin{array}{c}\text { Imp. to- } \\
\text { tales }\end{array}$ & $\begin{array}{l}\text { Parte por- } \\
\text { centual de } \\
\text { las imp. de } \\
\text { OSA en el } \\
\text { total in- } \\
\text { portado }\end{array}$ \\
\hline Productos alimenticios & 513 & 889 & 1.402 & 35,58 \\
\hline Bebidas y Tabaco & 1 & 4 & 5 & 20,00 \\
\hline $\begin{array}{l}\text { Materiailes crudos no co- } \\
\text { mestibles excepto los } \\
\text { combustibles }\end{array}$ & 119 & 130 & 249 & 47,79 \\
\hline Productos químicos & 461 & 398 & 859 & 53,66 \\
\hline $\begin{array}{l}\text { Artículos manufactura- } \\
\text { dos clasificados según }\end{array}$ & & & & \\
\hline el material & 445 & 606 & 1.051 & 42,34 \\
\hline Maquinaria y material & & & & \\
\hline de transporte & 7.411 & 4.673 & 12.084 & 61,33 \\
\hline $\begin{array}{l}\text { Articulos manufactura- } \\
\text { dos diversos }\end{array}$ & 634 & 618 & 1.252 & 50,63 \\
\hline TOTALES & 9.854 & 7.318 & 17.172 & 56,70 \\
\hline
\end{tabular}

Fuente: Banco Central de Venezuela. Informe Económico, 1969, Cuadro A. 200.

Del cuadro anterior concluimos que a pesar del sistema de restricciones cuantitativas establecido por el Gobierno de Venezuela, los productos importados descle los Estados Unidos se benefician de los aranceles preferenciales para los productos incluidos en la lista No 1, alcanzando un 56,70\% del total importado para estos rubros.

$\mathrm{Y}$ esta ventaja queda más claramente establecida al constatar que se trata de productos de no muy compleja tecnología, de difícil exportación para los Estados Unidos, por tanto el mercado venezolano constituye una alternativa no despreciable.

iv) Exportación del patrón americano de consumo

Durante bastante tiempo, los productos consumidos por los venezolanos fueron de origen norteamericano. Este efecto de demostración ha influido de forma determinante en la constitución del patrón de consumo venezolano.

Las ventajas para Estados Unidos de esta sutil exportación son manifiestas, ya que Venezuela en el desarrollo de su política: de sustitución de importaciones, orientó su industrialización a satis- 
facer el consumo doméstico de marca y aṛtículos al estilo. de yida. de USA.

Por ello, al profunclizar el proceso de sustitución de importaciones, nuestra tradición industrial nos condujo a transferir la dependencia. de las importaciones provenientes de los Estados Unidos, de los. bienes de consumo final a los bienes intermedios y de capital.

DESVENTAJAS PARA VENEZUELA

\section{i) Balanza de pagos deficilaria}

El análisis de la balanza de pagos con los Estados Unidos puede darnos alguna idea de la no reciprocidad del Tratado y la clara des; ventaja para Venezuela.

Según el estudio sobre lạ balanza de pagos entre Venezuela y los Estados Unidos elaborado por el Departamento de Investigaciones económicas del Banco Central de Venezuela, correspondiente al período 1959-1970, el total de nuestras exportaciones es de $13.927 \mathrm{mi}-$ llones de dólares y el total de nuestras importaciones es de 15.398; millones de dólares. La diferencia acumulada desfavorable a Venezuela es de 1.791 millones de clólares.

Veamos los saldos acumulados para el lapso 1959-1970:

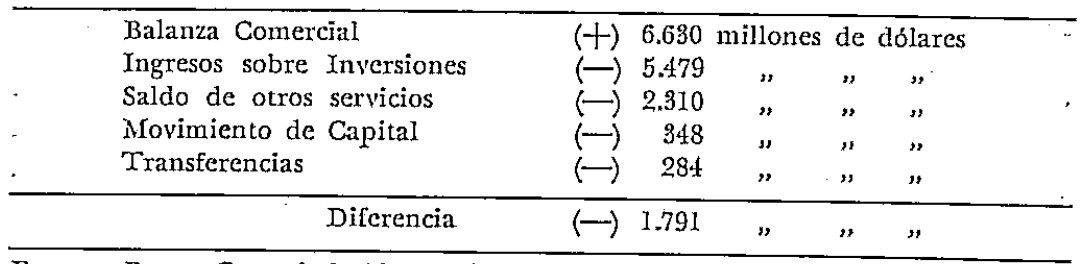

Fuente: Banco Central de Venezuela. Informe Económico 1970. P’ág. 145, Cuadro X-2.

La UNCTAD, descle 1964, ha reconocido que uno de los principios fundamentales que deben regir el comercio entre países en desarrollo y países industrializados es el de no Reciprocidad. Prueba de ello es el sistema general de preferencias no reciprocas y no discriminatorias. Mediante este sistema los países industrializados se comprometen a otorgar preferencias arancelarias a todos los países en vías de desarrollo. Por su parte estos últimos -y aquí está la no reci procidad-quedan en completa libertad para fijar el nivel arancelario más adecuado al desarrollo de sus respectivas economías. 
Luego, cuando se establece en el Tratado entre Venezuela y los Estados Unidos, "... mantener en sus relaciones comerciales el principio de igualdad..." el resultado es claramente injusto. Más aún, como las exportaciones de Venezuela (petróleo e hierro) son materias primas no renovables, la injusticia de la reciprocidad comercial es aún mayor, y es por ello que nos explicamos cómo Venezuela con un saldo positivo en su balanza comercial con los Estados Unidos de 6.630 millones de dólares, termina con un déficit de 1.791 millones de dólares en su balanza de pagos.

\section{ii) Costo social de la industrialización}

A partir de las violaciones del Tratado, en Venezuela se inicia un. consciente esfuerzo hacia la industrialización. En efecto, a partir de 1959 , se establece el sistema de restricciones cuantitativas a los productos contenidos en la lista No 1 . Es importante señalar que en esa oportunidad, y por virtud de la vigencia del Tratado, Venezuela no pudo utilizar como instrumento de política económica orientado hacia una efectiva protección, el arancel de aduanas. Por tanto, el Gobierno Nacional se vio entonces forzado a utilizar el instrumento de "licencia previa".

La "licencia previa" es el régimen mediante el cual el Gobierno Nacional establece condiciones y procedimientos administrativos a cumplir por parte del virtual importador, a fin de que se le conceda el permiso para importar determinada cantidad del producto sometido al régimen de restricciones cuantitativas.

Todo ello ha determinado el surgimiento de un complejo, lento y costoso aparato administrativo, que en ocasiones discrimina en favor del gran industrial en perjuicio del pequeño y mediano productor. Los grupos económicos poderosos pueden en consecuencia establecer una verdadera integración vertical de la industria, pues no sólo obtienen la licencia previa de los insumos necesarios sino también de los bienes finales de consumo presuntos competidores de aquellos que piensan producir. Tal ventaja les permite comercializar ambos productos (nacionales o importados), lo que a su vez determina la creación. de monopolios de explotación que conduce al manejo indiscriminado del parámetro de los precios. La política de industrialización así realizada no ha sido redistributiva sino por el contrario ha acrecentado el poder de los grupos económicos.

Por estas razones el costo social y político de la industrialización es difícilmente mensurable en números pero sí es demasiado apreciable para ser ignorado. El flujo del dinero sale del petróleo, de las entrañas de la tierra venezolana, deriva hacia el Estado y termina enriqueciendo a unos pocos grupos económicos. Esta transfe- 
rencia de capital fortalece y consolida las injusticias estructurales del país.

\section{iii) Dependencia tecnológica}

Como lo indicamos más arriba, la importación masiva de artículos norteamericanos implantó en Venezuela un patrón de consumo al estilo de vida de Norteamérica. Cuando en Venezuela se decide un proceso de industrialización en base a una política de sustitución de importaciones, no se duda sobre qué tipos de productos hay que fabricar ni tampoco sobre las patentes, marcas y tecnologías a utilizar. Se trata de fabricar los mismos productos existentes en el mercado pero "hechos en Venezuela".

La importación de tecnología impulsada por las razones anteriores, ha esterilizado la creatividad mínima del empresario venezolano. Por otra parte la constatación de que en la mayoría de los casos la transferencia tecnológica va acompañada de inversiones directas extranjeras, la mayoría norteamericanas, hace que la visión del problema se rodee de aspectos sorprendentes.

Ello ha significado que la adquisición de materias primas y bienes de capital de origen norteamericano suponga más del $50 \%$ de los insumos de origen extranjero que utiliza la industria que opera en el pais. De las patentes registradas en Venezuela en el año 1969, el $49,60 \%$ son norteamericanas y el $2,55 \%$ son venezolanas 2 . Hay empresas con capital norteamericano que pagan por concepto de patentes o "royalties" a sus casas matrices porcentajes anuales del $20 \%$, $50 \%, 60 \%$ y hasta $240 \%$ de su capital invertido. (Puede verse más detalles en el trabajo citado al pie de página). Asimismo las tecnologías importadas diseñadas para ahorrar mano de obra y para producir a una escala mayor que la requerida por el mercado venezolano constituyen un verdadero obstáculo para la industrialización del país. Precios elevados, alto nivel de desempleo, capacidad industrial ociosa $(40 \%)$, productos de baja calidad son índices de una política de industrialización nacional de pocos logros, dependiente en grado sumo y derivada en gran parte de la existencia del Tratado de 1952 con antecedentes en 1939.

iv) Pérdida de poder de negociación en los esquemas de integración ALALC y Pacto Andino

La cláusula de nación más favorecida (arts. 9 y 10 del Tratado) determina que las preferencias arancelarias concedidas a terceros

"Instituto de Comercio Exterior. "La inversión extranjera en Venezuela", Caracas, 1971. 
paises automáticamente se aplican a los firmantes del Convenio, Venezuela y los Estados Unidos.

Los tratados comerciales firmados con terceros países han supuesto la extensión automática de las reducciones arancelarias de la Lista No 1 a esos paises sin obtener en consecuencia, una adecuada compensación. Por otra parte, el congelamiento de los niveles arancelarios de los productos incluidos en la lista $\mathrm{N} \% \mathrm{l}$, han dificultado el manejo de una política arancelaria racional y ello ha incidido en forma desfavorable en los beneficios de la participación de Venezuela en la ALALC, a la vez que introducia obstáculos difíciles de salvar, para las negociaciones con los países firmantes del Acuerdo de Cartagena.

Conviene señalar que de acuerdo con el articulado del Tratado de Montevideo, Venezuela estaba obligada a extender a todos los paises signatarios todas las ventajas concedidas a los Estados Unidos en la lista $N^{0} 1$, sin reciprocidad alguna.

Por último, respecto al Acuerdo de Cartagena, el problema era mayor, pues la existencia del arancel externo común, obligaba a variar los niveles arancelarios creando una situación de incompatibilidad manifiesta.

Por todos los aspectos reseñados impostergable resultaba para Venezuela la denuncia del Tratado con los Estados Unidos. Y en efecto, el $1^{9}$ de enero del presente año, el Gobierno Nacional procedió a la formal denuncia del mismo. 